"El principio pro requirente en la Sentencia del Tribunal Constitucional sobre la Ley Orgánica Constitucional del Tribunal Constitucional”

\title{
EL PRINCIPIO PRO REQUIRENTE EN LA SENTENCIA DEL TRIBUNAL CONSTITUCIONAL SOBRE LA LEY ORGÁNICA CONSTITUCIONAL DEL TRIBUNAL CONSTITUCIONAL*
}

\author{
Francisco Zúñiga Urbina \\ Profesor de Derecho Constitucional \\ Universidad de Chile y Universidad Diego Portales \\ zdmc@zdmcabogados.cl
}

RESUMEN: A través del presente artículo se analiza la jurisprudencia del Tribunal Constitucional sobre el principio pro requirente, sus alcances y problemas, y además, se analiza la sentencia de autocontrol de constitucionalidad referida a la Ley $\mathrm{N}^{\circ} 20.381$.

PALABRAS CLAVE: Control de constitucionalidad, principio pro requirente, deferencia, auto limitación y activismo judicial.

ABSTRACT: Trough this article examines the jurisprudente of Constitucional Court over the "pro actione" principle, importance and problems, and moreover, examine the sentence of constitutional self-control refer an Act $\mathrm{N}^{\circ} 20.381$.

KEY WORDS: Constitutional control, "pro actione” principle, deference, self restraint and judicial activism.

\footnotetext{
Ponencia del Seminario "Reflexiones sobre la Ley Orgánica Constitucional del Tribunal Constitucional y su Control de Constitucionalidad", organizado por el Centro de Estudios Constitucionales de la Universidad de Talca y la Asociación Chilena de Derecho Constitucional, realizado los días 21 y 22 de octubre de 2009.
} 


\section{INTRODUCCIÓN}

Resulta una obviedad a la que no podemos resistir afirmar: el Tribunal Constitucional es un "tribunal", un órgano jurisdiccional, con una competencia tasada de conflictos, en que la acción de inconstitucionalidad pone en marcha un proceso de constitucionalidad, en la que cristaliza un juicio de legitimidad o de control de constitucionalidad concernientes a actos estatales, que se verifica a través de una decisión del colegio de jueces, que adopta la forma de una sentencia. Bajo esta perspectiva el control de constitucionalidad puede estar abierto a toda la sociedad y no sólo a órganos estatales legitimados, y cuando se opta por la lex lata por restringir la legitimación procesal activa, es esencial admitir a la tutela judicial del Derecho de la Constitución a las minorías, quienes en la dialéctica del proceso político democrático tienen la llave del control del poder político y sus detentadores (Kelsen). ${ }^{1}$ Precisamente el principio pro requirente nos sitúa ante una actitud pro admitiere del Tribunal Constitucional, proclive a entender el rol de las minorías en el proceso político democrático.

Asimismo, desde la perspectiva procesal el principio pro requirente debe estar situado en una perspectiva pro actione, que concibe la acción como "...un derecho humano a la justicia” (Fix Zamudio), es decir, una garantía constitucional procesal de acceso a la tutela judicial del derecho asegurada en el artículo $19 \mathrm{~N}^{\circ} 3$ de la Constitución, y en que la acción como derecho autónomo encuentra soporte en el derecho de petición (Couture), derecho fundamental asegurado en el artículo $19 \mathrm{~N}^{\circ} 14$ de la misma Carta. En consecuencia, el principio pro requirente hereda todo el debate doctrinal acerca de la acción en el procesalismo científico que viene a concebirla independiente del derecho sustantivo y en una perspectiva publicística enderezada a la tutela del derecho en el proceso (Chiovenda, Rocco, Calamandrei y Carnelutti, entre otros). ${ }^{2}$

En este mismo orden de ideas, es menester precisar que el Tribunal Constitucional no es un órgano consultivo de constitucionalidad de actos estatales, ni la acción, instrumentada mediante un "requerimiento", es un mecanismo para formular consultas a esta Judicatura o para formular impugnaciones potenciales, virtuales o probables acerca de la constitucionalidad del acto estatal. El Tribunal Constitucional es un órgano jurisdiccional supremo cuya competencia está enderezada a resolver conflictos constitucionales ciertos, específicos, a partir de los cuales se configuran vicios de inconstitucionalidad material, formal y/o competencial; y no para trazar orientaciones o exhortaciones acerca del obrar del legislador democrático (STC rol N²3, de 26 de septiembre de 1984).

En razón de lo anterior la Ley $\mathrm{N}^{\circ} 17.997$, modificada por la Ley $\mathrm{N}^{\circ} 20.381$, Orgánica Constitucional del Tribunal Constitucional (LOCTC) fija en el artículo 38 los órganos legitimados procesalmente para deducir la acción (Presidente de la República, cualquiera de las cámaras o una cuarta parte de sus miembros en ejercicio), en el artículo

\footnotetext{
KeLSEN (2001).

2 Fix Zamudio (1985), p. 13. También Couture (1958), p. 57.
} 
38 bis el término u "oportunidad" para formular el requerimiento, conservando el artículo 39 un conjunto de requisitos de admisibilidad de los requerimientos formulados conforme al artículo $93 \mathrm{~N}^{\circ} 3$ (anterior artículo $82 \mathrm{~N}^{\circ} 2$ ) de la Constitución. El alto estándar exigido al "requerimiento" para todas las "cuestiones de constitucionalidad" estriba en que la acción impetrada debe explicitar sus fundamentos y fundar el o los vicios de inconstitucionalidad que sirven para fundar la impugnación, todo en atención a los principios de bilateralidad y de presunción de constitucionalidad de la ley. En virtud del principio de bilateralidad los legitimados procesalmente deben tener oportuno y cabal conocimiento de las argumentaciones y fundamentos del requerimiento para formular sus observaciones (artículo 41 de la LOCTC). Asimismo, en virtud del principio de presunción de constitucionalidad de los actos estatales que se impugnan, el acto goza de una presunción iuris tantum acerca de su regularidad constitucional y mientras no exista una fuerte o sólida convicción acerca de los vicios de inconstitucionalidad que lo afecten. Como bien anota el administrativista español Eduardo García de Enterría acerca de la presunción de constitucionalidad del obrar del legislador democrático: "primero, una confianza otorgada al legislativo en la observancia y en la interpretación correcta de los principios de la Constitución; en segundo término, que una ley no puede ser declarada inconstitucional más que cuando exista 'duda razonable' sobre su contradicción con la Constitución; tercero, que cuando una ley esté redactada en términos tan amplios que puede permitir una interpretación constitucional habrá que presumir que, siempre que sea 'razonablemente posible', el legislador ha sobreentendido que la interpretación con la que habrá de aplicarse dicha ley es precisamente la que permitirá mantenerse dentro de los límites constitucionales". ${ }^{3}$

En suma, la acción de inconstitucionalidad es si se permite una licencia con afanes descriptivos es "una moneda de dos caras", una cara de la moneda son los estándares formales y argumentativos que debe reunir el requerimiento para darle peso a la pretensión, que importa fundar y establecer razonablemente la inconstitucionalidad del acto estatal, y que guardan directa relación con la bilateralidad de la audiencia y presunción de legitimidad del acto que se impugna y la otra cara de la moneda es asegurar, dentro del campo de la legitimación procesal activa, que la activación del Tribunal mediante el requerimiento no se verá frustrada por requisitos formales o no previstos por el Poder Constituyente para acceder a la tutela judicial de la Constitución.

El funcionamiento del principio pro requirente hasta ahora examinado en relación al viejo artículo $82 \mathrm{~N}^{\circ} 2$ de la Constitución (actual artículo $93 \mathrm{~N}^{\circ} 3$ ) y artículo 39 de la LOCTC, no obstante los requisitos de forma y de fondo de la "cuestión de constitucionalidad”, en "algunas ocasiones” importa que el Tribunal Constitucional relaje la exigencia de estos requisitos para favorecer su avocación al asunto (Carmona).

En el pasado el mentado principio pro requirente es formulado por la doctrina (Carmona, Zapata) con motivo de la jurisprudencia del Tribunal Constitucional referida a

3 García de Enterría (1985), p. 96. 
“cuestiones de constitucionalidad" del primitivo artículo 82 , inciso primero, $\mathrm{N}^{\circ} 2$, e inciso cuarto de la Constitución antes de la reforma constitucional de 2005, promulgada por la Ley $\mathrm{N}^{\circ} 20.050,{ }^{4}$ interesándonos en el presente con motivo de la jurisprudencia de Tribunal; ya que en el caso en análisis, la STC rol $\mathrm{N}^{\circ} 1.288 / 2008$, de 25 de agosto de 2009, de autocontrol de constitucionalidad, la Judicatura Constitucional vuelve a aplicar el principio pro requirente para declarar inconstitucionales un bloque de normas, favoreciendo pro actione la tutela judicial de la Constitución y por cierto, su propia competencia frente al peligro de desconstitucionalización y vaciamiento legislativo.

\section{PRINCIPIO PRO REQUIRENTE EN LA JURISPRUDENCIA DEL TRIBUNAL CONSTITUCIONAL}

En nuestro medio Carmona define el principio pro requirente en los siguientes términos: "consiste en que el Tribunal no exige requisitos para admitir válidamente un requerimiento a tramitación o interpreta, para declararlo procedente, dichos requisitos a favor de quienes requieren". ${ }^{5}$ Habría que agregar a esta definición del principio pro requirente, circunscribir los requisitos de la acción de inconstitucionalidad reservados al texto constitucional, entendiendo a ésta como una acción o derecho a la tutela judicial y no una potestad de los órganos estatales legitimados (STC rol N ${ }^{\circ} 207$, de 10 de febrero de 1995, y disidencia del ministro señor Valenzuela y del abogado integrante señor Soto en STC rol N²69, de 17 de diciembre de 1997).

Como se ha dicho en nuestro medio las manifestaciones del principio pro requirente han sido estudiadas por Carmona, quien críticamente comenta diversas sentencias del Tribunal Constitucional sobre la materia (SSTC rol $\mathrm{N}^{\circ} 23$, de 26 de septiembre de 1984; rol $\mathrm{N}^{\circ} 228$, de 15 de diciembre de 1995, entre otras), por lo que no reiteraremos dicho análisis y sus conclusiones que compartimos en buena medida.

En este trabajo, a efecto de comentar en el próximo capítulo la sentencia del Tribunal Constitucional de autocontrol de constitucionalidad, nos limitaremos aquí a recoger algunos aspectos básicos acerca de la acción de inconstitucionalidad, ventilada en la "cuestión de constitucionalidad", en la que históricamente emerge el principio pro requirente en la jurisprudencia del Tribunal Constitucional.

1. En la STC rol $280 / 1998$, de 20 de octubre de 1998 , considerandos $4^{\circ}$ y $5^{\circ}$ fija los términos de la legitimación procesal y la posibilidad de ampliar el requerimiento:

“4. Que, en referencia al otrosí del escrito de fojas 50, en que el abogado patrocinante, profesor Teodoro Ribera, amplía el requerimiento, cabe razonar en cuanto a que sólo los requirentes son los titulares de la acción procesal para activar la

\footnotetext{
4 Su desarrollo de obligada consulta es realizado por CARMONA (2001), pp. 564-600.

5 Carmona (2001), p. 566.
} 
jurisdicción de este Tribunal. En efecto, en relación al conflicto de constitucionalidad de que se trata, el artículo 82, inciso cuarto, expresa que, en el caso del $\mathrm{N}^{\circ} 2$, el Tribunal sólo podrá conocer de la materia cuando es requerido por una cuarta parte de los miembros en ejercicio de cualquiera de las Cámaras. Esta norma se encuentra complementada por el artículo 38 de la Ley $\mathrm{N}^{\circ} 17.997$, Orgánica Constitucional de este Tribunal, que expresa, en su inciso cuarto: "Si el requerimiento emanare de una cuarta parte de los miembros en ejercicio de una de las Cámaras, podrá formularse por conducto del Secretario de la respectiva Corporación o directamente ante el Tribunal. En uno y otro caso, deberán firmar los parlamentarios ocurrentes y autorizarse su firma por el Secretario señalado o por el del Tribunal Constitucional. Siempre deberá acreditarse que los firmantes constituyen a lo menos el número de parlamentarios exigidos por la Constitución. En el respectivo requerimiento deberá designarse a uno de los parlamentarios firmantes como representante de los requirentes en la tramitación de su reclamación”.

Constituye un hecho del proceso que el escrito en que se complementa el requerimiento ampliándolo, sólo aparece firmado por el abogado patrocinante y mandatario, quien a juicio de este Tribunal, carece de titularidad para modificar los términos del requerimiento planteado en lo que se refiere a su objeto y causa.

Esta conclusión se desprende indubitadamente del tenor de la disposición recién citada, que otorga la representación de los requirentes al o a los parlamentarios que ellos mismos designan al efecto, y que en el caso sub lite, fueron los Diputados Rodrigo Álvarez y Carlos Kuschel, a quienes los 31 parlamentarios requirentes designaron "como nuestros representantes para todos los efectos legales";

$5^{\circ}$. Que, la única exigencia que contiene el artículo 38, de la Ley Orgánica Constitucional de este Tribunal, en relación a la comparecencia, es que en el respectivo requerimiento se designe a uno de los parlamentarios firmantes como representantes de los requirentes en la tramitación de su reclamación.

Sin embargo, ha sido una práctica autorizada por este Tribunal la de aceptar, a los parlamentarios requirentes, la designación de un abogado patrocinante y mandatario para que los represente en la tramitación del proceso en que se sustancia la cuestión de constitucionalidad, facilitándoles así su defensa, mas ello no constituye una exigencia ni solemnidad a cumplir, toda vez que el artículo 38 recién citado, en su carácter de norma procesal propia de una ley orgánica constitucional tiene un distinto ámbito de acción que el contenido en el artículo $2^{\circ}$ de la Ley $\mathrm{N}^{\circ} 18.120$, que contiene normas generales sobre comparecencia en juicio, por lo cual, por su naturaleza y especialidad prevalece sobre ella.

Encontrándose precisados por el texto de la Constitución Política y por las normas procesales contenidas en el Título II, Párrafo II, de la Ley $\mathrm{N}^{\circ} 17.997$, quienes son los titulares de la acción para someter a la decisión de este Tribunal Constitucional, conflictos de constitucionalidad que surjan durante la tramitación de un proyecto de ley, cabe concluir que sólo los requirentes tienen legitimidad procesal para ampliar su requerimiento y que tal facultad no es delegable.

El mandatario judicial, en virtud de los razonamientos precedentemente expuestos, carece de tales atribuciones. 
Siendo así, el Tribunal sólo considerará lo expresado en el requerimiento mismo, y desestima la breve complementación contenida en el ya citado escrito de fojas 50 .

Si acepta que el mandatario pueda acompañar antecedentes al proceso para darle curso progresivo, lo que en el hecho ocurrió, toda vez que con motivo de lo principal de la referida presentación el requerimiento fue declarado admisible y se acogió a tramitación, más diversa es la situación del citado otrosí en que, como ya se manifestó altera los fundamentos y peticiones del requerimiento, materias que son privativas de los parlamentarios requirentes; [...]".

2. En la STC rol No $259 / 1997$, de 26 de septiembre de 1997 , considerando $6^{\circ}$ se sostiene que la objetividad de un vicio de inconstitucionalidad es central para impetrar un requerimiento, no admitiéndose su convalidación:

“ $6^{\circ}$. Que, por último, la circunstancia que el Senado haya aprobado el proyecto de ley en estudio propuesto por la Comisión Mixta, no lo inhabilita para plantear un requerimiento a fin de que se declare la inconstitucionalidad del Título II del mismo, ya que tal aprobación no tiene la virtud de convalidar un vicio de inconstitucionalidad que pudiera afectar al proyecto aprobado. Sostener lo contrario, significa que un acuerdo de una Cámara Legislativa prevalece sobre la preceptiva constitucional, lo cual resulta definitivamente inadmisible. Lo anterior, es aún más claro, habida consideración de que el Senado, conjuntamente con aprobar el proyecto de ley, acordó recurrir a este Tribunal a fin de que se pronunciara sobre la constitucionalidad de su Título II.

A mayor abundamiento, cabe señalar que las normas de la Constitución deben interpretarse de manera tal que exista entre ellas la debida correspondencia y armonía, y ninguna interpretación de la Carta Fundamental puede conducir a dejar sin aplicación un determinado precepto de ella. En consecuencia, para dar debido cumplimiento a tales normas elementales de hermenéutica jurídica, los artículos 67 y 68 de la Constitución complementados por el artículo 31 de la Ley $\mathrm{N}^{\circ} 18.918$, en cuanto obligan a las Cámaras Legislativas a pronunciarse sobre la totalidad del proyecto propuesto por la Comisión Mixta, deben entenderse sin perjuicio de la facultad de los titulares legitimados en el artículo 82, inciso cuarto, de la Constitución, para promover una cuestión de constitucionalidad, conforme al número $2^{\circ}$ de dicho precepto, aún en relación a aquellos artículos del proyecto respecto de los cuales hubieren tenido que consentir, por la aplicación de las rígidas normas a que deben someterse en la aprobación o rechazo de las proposiciones de la Comisión Mixta respectiva.

Por las consideraciones expuestas, este Tribunal desestima las observaciones formuladas por el Presidente de la República y por la Cámara de Diputados respecto de la admisibilidad del requerimiento.”.

3. En la STC rol $\mathrm{N}^{\circ} 269 / 1997$, de 17 de diciembre de 1997 , considerandos $9^{\circ}$ y $14^{\circ}$ se resume la doctrina dominante de nuestra jurisprudencia constitucional acerca de la preparación de la "cuestión de constitucionalidad": 
“9'. Que en lo anterior está implícito que quienes deducen un requerimiento de inconstitucionalidad hayan mantenido durante la tramitación del proyecto una conducta coherente con el reproche que formulan.

No es lógicamente admisible que quien da su voto explícito en favor de una disposición del proyecto, cuestione su constitucionalidad ante este Tribunal; carece, en consecuencia, de titularidad activa."

“14". Que este Tribunal estima que en el caso sub lite no se da el presupuesto anteriormente indicado porque tres de los Senadores que suscriben el requerimiento carecen de titularidad activa, atendidos los razonamientos precedentes.”.

También el Tribunal Constitucional se hace cargo de determinar la oportunidad procesal para interponer el requerimiento impugnatorio en las "cuestiones de constitucionalidad" según la vieja-nueva fórmula: "[...] antes de la promulgación de la ley" (oración final del inciso cuarto del antiguo artículo 82, actual inciso cuarto del artículo 93, y que es objeto de interpretación auténtica mediante nuevo artículo 38 bis de la Ley $\mathrm{N}^{\circ} 17.997$ orgánica constitucional del Tribunal Constitucional modificada la "ley adecuatoria” de la LOCTC a la reforma constitucional de 2005: la Ley $\mathrm{N}^{\circ} 20.381$ ).

1. A este respecto, en la STC rol $N^{\circ} 23 / 1984$, de 26 de septiembre de 1984 , considerando $4^{\circ}$, se precisan los requisitos generales para plantear la cuestión de constitucionalidad:

“4. Que, en consecuencia, de conformidad con los preceptos transcritos en el considerando anterior, las condiciones esenciales que deben concurrir copulativamente para que el Tribunal pueda ejercer la atribución que se le confiere, son las siguientes:

a) Que se suscite una cuestión de constitucionalidad, esto es, un desacuerdo, una discrepancia sobre la preceptiva constitucional entre los órganos colegisladores. Tal discrepancia puede surgir entre el Poder Ejecutivo y el Poder Legislativo o en el seno mismo del segundo. El artículo 82 inciso $4^{\circ}$ y la disposición vigésima segunda transitoria señalan, taxativamente, quiénes están legitimados para formular el requerimiento;

b) Que la desigual interpretación de las normas constitucionales, en el caso en estudio, se produzca en relación a un proyecto de ley o a una o más de sus disposiciones;

c) Que la discrepancia que se suscite sobre la preceptiva constitucional en relación a las normas de un proyecto de ley sea precisa y concreta. Esta condición delimita la competencia del Tribunal para resolver el asunto sometido a su consideración y adquiere especial relevancia, si se recuerda que la acción sólo puede ser deducida por titulares nominativamente señalados por la Carta Fundamental y que el Tribunal no puede actuar de oficio, debiendo ajustar su resolución estrictamente al "objeto pedido" en el requerimiento, $y$

d) Que la cuestión de constitucionalidad se suscite "durante la tramitación del proyecto de ley”. En consecuencia, el período en que puede formularse el re- 
querimiento, durante el proceso de formación de la ley, se extiende desde el momento en que el proyecto respectivo ha iniciado su tramitación legislativa y hasta aquel en que se ha "producido la sanción expresa, tácita o forzada de la ley, es decir, ya aprobada por el Presidente o transcurrido el plazo para observarla o comunicado por la Cámara de origen el resultado de las observaciones que se hubieren formulado" (Silva B. Alejandro, El Tribunal Constitucional, Estudio contenido en la obra «La Reforma Constitucional de 1970", pág. 249); [...]”.

2. La STC rol N $\mathrm{N}^{\circ} 207 / 1995$, de 10 de febrero de 1995 , considerandos $2^{\circ}, 4^{\circ}, 5^{\circ}$ y $6^{\circ}$, pro admitiere y pro requirente abre la posibilidad de impugnar un proyecto de ley, flexibilizando la oportunidad para entablarlo, en los términos siguientes:

"SEGUNDO. Que dicho requerimiento ha sido formulado el día 22 de enero de 1995, mediante presentación entregada al Secretario de este Tribunal, esto es, con anterioridad a que el día 23 de enero, el Presidente de la República, luego de recibir el Oficio de la $\mathrm{H}$. Cámara de Diputados por el que le informara de la aprobación del referido proyecto de ley, procediera a suscribir el respectivo Decreto Supremo de promulgación y a solicitar la correspondiente toma de razón por la Contraloría General de la República; [...]".

“CUARTO. Que en virtud de lo así establecido, este Tribunal se encuentra requerido oportunamente para resolver la cuestión de constitucionalidad sometida a su conocimiento, dado que el requerimiento ha sido "formulado antes de la promulgación de la ley", como lo exige el inciso cuarto del artículo 82 de la Constitución Política;

QUINTO. Que el hecho de haber sido "formulado" debe entenderse en la propia acepción de este término, siguiendo lo que al respecto señala el Diccionario de la Real Academia Española, al otorgarle a este vocablo la significación de "expresar" o "manifestar" o "reducir a términos claros y precisos un mandato, una proposición...", lo que ha quedado suficientemente establecido en el texto del requerimiento de autos;

SEXTO. Que corrobora lo anterior la propia disposición del artículo 40 de la Ley $N^{\circ}$ 17.997, Orgánica del Tribunal Constitucional, cuando señala que «Recibido el requerimiento por el Tribunal, se comunicará al Presidente de la República la existencia de la reclamación ...", términos éstos que reproducen con exactitud lo que ya contemplaba la antigua disposición aplicable al Tribunal creado en 1970. Al reconocer la Constitución de 1925 y la legislación actual la existencia de la reclamación por el solo hecho de ser recibida, reitera la significación y los efectos derivados de su sola formulación; [...]".

En suma el principio pro requirente paulatinamente se abrió camino en la jurisprudencia del Tribunal Constitucional, fundado en que una interpretación restrictiva del antiguo artículo 82 (actual 93) de la Constitución, la que para el intérprete judicial no se concilia con el espíritu de la Carta, que es permitir a los órganos estatales legitimados requerir al Tribunal la "justiciabilidad” del Derecho de la Constitución. Esta justicia- 
bilidad de la Constitución debe ser sin requisitos innecesarios o formalidades excesivas, que dificulten o impidan la guarda de la supremacía, valor y eficacia normativa iusfundamental. Por ello mismo, como bien observa Carmona, el principio pro requirente, entiende que entablar requerimientos no es fruto de una potestad regida por el principio de legalidad, sino un "derecho de los parlamentarios" surgida la cuestión de constitucionalidad.

Lo anterior a nuestro juicio es central, por que permite situar el principio pro requirente en su dimensión procesal constitucional, como una manifestación de la tutela judicial de la Constitución, tutela que se arbitra a través de un plexo de garantías procesales constitucionales que conforman el sistema de jurisdicción constitucional. Luego, el principio pro requirente está en la base de la acción de inconstitucionalidad como derecho subjetivo público del legitimado procesalmente para activar al Tribunal Constitucional, para que éste ejerza su competencia en el proceso constitucional.

Ello no obsta, a una mirada más crítica que permite observar en el principio pro requirente, sea un comodín o un expediente a través del cual un Tribunal Constitucional activo defienda su competencia y la tutela judicial de la Constitución.

Incluso más desde la perspectiva del origen del principio pro requirente de la mano de las "cuestiones de constitucionalidad" su surgimiento y consolidación está ligado a la funcionalidad del Tribunal Constitucional, al partir la transición política a la democracia en 1990, como dispositivo autoritario y contramayoritario, es decir, como hemos afirmado antes en otros lugares el Tribunal, recogiendo una expresión que hizo fortuna en Francia para designar el rol del Consejo Constitucional, no es el "perro guardián" en las puertas del Congreso Nacional, sino el custodio de las potestades normativas del Gobierno frente a la potestad legislativa y en especial de las "leyes de super-mayoría" que le dan a la minoría, reforzada por una quinta parte del Senado integrada por senadores institucionales herencia del régimen autoritario, la llave de un segmento relevante de la legislación; por lo que la vía franca a la minoría parlamentaria, heredera del autoritarismo neoliberal del régimen anterior y su Constitución, en la guarda del orden constitucional político, económico y social es su más elemental consecuencia. ${ }^{6}$

Todo ello importa una cierta ambivalencia, que no podemos obviar con simplismo o escapismo teórico-práctico, en el análisis del principio pro requirente y de la actitud pro admitiere del Tribunal Constitucional.

\section{SENTENCIA DEL TRIBUNAL CONSTITUCIONAL Y PRINCIPIO PRO REQUIRENTE}

La sentencia de autocontrol de constitucionalidad de fecha 25 de agosto de 2009 de la "ley adecuatoria" de la Ley $N^{\circ} 17.997$ orgánica constitucional del Tribunal Cons-

6 ZúNIIGA (2002). 
titucional (LOCTC), a la reforma constitucional de 2005 que "refunda" o instituye un "nuevo" Tribunal Constitucional, promulgada como Ley $\mathrm{N}^{\circ} 20.381$, es ejemplar en su capítulo de declaración de inconstitucionalidad de normas del proyecto de ley así como en su capítulo de "entendidos" (capítulo I y III del decisum respectivamente), en la medida que éstos reconducen al principio pro requirente, a la defensa de una competencia tasada en la Constitución de esta Judicatura y a la mayor expansión de la tutela judicial del Derecho de la Constitución. Luego, decir que se trata de "una sentencia mala y fea”, como lo hace un comentarista de nuestro medio (R. Letelier W.), más allá de la agudeza o acierto del comentario, es a la luz del principio pro requirente una exageración, ya que este prisma de análisis nos permite aquilatar y cargar las tintas en los aspectos más positivos de la decisión del autocontrol de constitucionalidad.

\section{Sentencia del Tribunal Constitucional (STC rol No $1.288 / 2008)$.}

1.1. En cuanto a las inconstitucionalidades fundadas en un principio pro admitiere y pro requirente (artículos 41 bis, 46 B, 47, 48 bis y 50 bis); ${ }^{7}$ éstas son el primer

7 "Artículo 37 C. Dentro del plazo de cinco días, contado desde que el requerimiento sea acogido a tramitación, el Tribunal se pronunciará sobre la admisibilidad o inadmisibilidad del mismo. Si el requirente pide alegar acerca de la admisibilidad, y en virtud de lo dispuesto en el artículo $32 \mathrm{~B}$ el Tribunal acoge la solicitud, dará traslado de esta cuestión, por tres días, al tribunal que haya dictado el auto acordado impugnado y a los órganos y las personas legitimados.

Procederá declarar la inadmisibilidad de la cuestión de inconstitucionalidad, en los siguientes casos:

$1^{\circ}$ Cuando el requerimiento no es formulado por una persona u órgano legitimado;

$2^{\circ}$ Cuando se promueva respecto de un auto acordado o de una de sus disposiciones, que hayan sido declarados constitucionales en una sentencia previa dictada de conformidad a este Párrafo y se invoque el mismo vicio materia de dicha sentencia;

$3^{\circ}$ Cuando carezca de fundamento plausible;

$4^{\circ}$ Cuando no exista gestión, juicio o proceso penal pendiente, en los casos en que sea promovida por una parte o persona constitucionalmente legitimada, y

$5^{\circ}$ Cuando no se indique la manera en que el auto acordado afecta el ejercicio de los derechos constitucionales del requirente, en los casos en que sea promovida por una parte o persona constitucionalmente legitimada.

Declarada la inadmisibilidad por resolución fundada, ésta será notificada a quien haya recurrido y el requerimiento se tendrá por no presentado, para todos los efectos legales." (destacado agregado).

"Artículo 41 bis. Dentro del plazo de cinco días, contado desde que el requerimiento sea acogido a tramitación, el Tribunal se pronunciará sobre la admisibilidad del mismo. Si el requirente pide alegar acerca de la admisibilidad, y en virtud de lo dispuesto en el artículo 32 B el Tribunal asî lo dispone, dará traslado de esta cuestión, por dos días, a los órganos legitimados.

Procederá declarar la inadmisibilidad en los siguientes casos:

$1^{\circ}$ Cuando el requerimiento no es formulado por un órgano legitimado.

$2^{\circ}$ Cuando la cuestión se promueva con posterioridad a las oportunidades indicadas en el artículo 38 bis.

$3^{\circ}$ Cuando en los antecedentes de la tramitación del proyecto de ley, de reforma constitucional o tratado impugnado no conste haberse suscitado expresamente una cuestión de constitucionalidad a su respecto.

$4^{\circ}$ Cuando la cuestión carezca de fundamento plausible.

Declarada la inadmisibilidad por resolución que deberá ser fundada, ésta será notificada a quien haya recurrido y el requerimiento se tendrá por no presentado, para todos los efectos legales. 
capítulo del decisum de la sentencia y tal inconstitucionalidad-sanción es declarada por el Tribunal porque son normas o reglas orgánico-constitucionales de procedi-

La resolución que declare la admisibilidad o inadmisibilidad del requerimiento no será susceptible de recurso alguno."(destacado agregado).

“Artículo 46 B. Dentro del plazo de cinco días, contado desde que el requerimiento sea acogido a tramitación, el Tribunal se pronunciará sobre la admisibilidad del mismo, conforme a las reglas del Párrafo 3. Si el requirente pide alegar acerca de la admisibilidad, y en virtud de lo dispuesto en el artículo 32 B el Tribunal asî lo dispone, dará traslado de esta cuestión, por cinco días, a los órganos legitimados.

Procederá declarar la inadmisibilidad en los siguientes casos:

$1^{\circ}$ Cuando el requerimiento no es formulado por un órgano legitimado.

$2^{\circ}$ Cuando la cuestión sea promovida extemporáneamente.

$3^{\circ}$ Cuando del oficio de representación del Contralor conste que el decreto con fuerza de ley no ha sido objetado de inconstitucionalidad.

$4^{\circ}$ Cuando la cuestión promovida por una de las Cámaras o una cuarta parte de sus miembros en ejercicio se funde en alegaciones de legalidad.

$5^{\circ}$ Cuando la cuestión carezca de fundamento plausible.”(destacado agregado).

"Artículo 47 bis (47). Para ser acogido a tramitación, el requerimiento deberá cumplir con las exigencias señaladas en el inciso primero del artículo 39 y en el inciso segundo de este artículo, y deberá acompañarse a él la publicación en el Diario Oficial del decreto que fija el día de la consulta plebiscitaria.".

El requerimiento deberá indicar, además, si la cuestión se refiere a la procedencia de la consulta plebiscitaria, a su oportunidad o a los términos de la misma, precisando los aspectos específicos de la impugnación y su fundamento.

Procederá declarar la inadmisibilidad de la cuestión si no es formulada por un órgano legitimado, si es promovida extemporáneamente, carece de fundamento plausible o se refiere a materias de la competencia del Tribunal Calificador de Elecciones.

Si la sentencia resolviere que el plebiscito es procedente, deberá fijar en la misma resolución el texto definitivo de la consulta plebiscitaria, manteniendo la forma dispuesta en el decreto de convocatoria o modificándola, en su caso.

La sentencia deberá publicarse en la forma y plazo establecidos en el artículo 31 bis."(destacado agregado). “Artículo 48 bis. Dentro del plazo de diez días, contado desde que el requerimiento se acoja a tramitación o desde que concluya la vista del incidente, en su caso, el Tribunal se pronunciará sobre su admisibilidad. Si el requirente pide alegar acerca de la admisibilidad, y en virtud de lo dispuesto en el artículo 32 B el Tribunal así lo dispone, dará traslado de esta cuestión al Presidente de la República y al Contralor General de la República, como órganos constitucionales interesados, por el plazo de cinco días.

La declaración de inadmisibilidad procederá cuando la cuestión sea promovida extemporáneamente, cuando no sea formulada por un órgano legitimado, cuando se constate que la promulgación de la ley cuya omisión se alega ha sido efectuada y cuando carezca de fundamento plausible. Esta resolución será fundada.

La resolución que declare la admisibilidad o inadmisibilidad del requerimiento no será susceptible de recurso alguno."(destacado agregado).

"Artículo 50 bis. Para ser admitido a tramitación, el requerimiento deberá cumplir con las exigencias señaladas en el inciso primero del artículo 39 y a él deberá acompañarse la publicación del decreto impugnado.

Procederá declarar la inadmisibilidad de la cuestión, en los siguientes casos:

$1^{\circ}$ Cuando el requerimiento no es formulado por un órgano legitimado;

$2^{\circ}$ Cuando se promueva extemporáneamente;

$3^{\circ}$ Cuando se funde en vicios de ilegalidad;

$4^{\circ}$ Cuando se alegue exceso de la potestad reglamentaria autónoma y no fuere promovida por una de las Cámaras;

$5^{\circ}$ Cuando el vicio invocado afecte a un precepto legal vigente y no al decreto supremo impugnado, y

$6^{\circ}$ Cuando carezca de fundamento plausible. 
miento que imponen como requisito de la acción conducente a la declaración de inconstitucionalidad: "fundamento plausible".

Sobre el fundamento o ratio decidendi de la decisión relativa a las inconstitucionalidades de los artículos indicados del proyecto de ley, la sentencia del Tribunal Constitucional indica:

"VIGESIMOQUINTO. Que, como puede apreciarse, en dichas disposiciones se indica quiénes tienen legitimación activa para deducir los respectivos requerimientos y la oportunidad y circunstancias en que pueden formularlos, pero en modo alguno se condiciona o subordina la facultad que poseen los titulares de la acción para interponerla a las exigencias contenidas en los artículos $37 \mathrm{C}$, inciso segundo, $N^{\circ} 3^{\circ}, 41$ bis, inciso segundo, $N^{\text {os }} 3^{\circ}$ y $4^{\circ}, 46 \mathrm{~B}$, inciso segundo, $\mathrm{N}^{\text {os }} 3^{\circ}$ y $5^{\circ}, 47$ que pasa a ser 47 bis, inciso tercero, 48 bis, inciso segundo, y 50 bis, inciso segundo, $\mathrm{N}^{\circ} 6^{\circ}$, antes transcritos, en cuanto a que se haya planteado expresamente una cuestión de constitucionalidad durante la tramitación del proyecto o tratado respectivo; a que en el oficio de representación del Contralor conste que el decreto con fuerza de ley ha sido objetado de inconstitucionalidad, o a que la cuestión tenga fundamento plausible. Más aún, en términos tales que si estas exigencias no se cumplen, la acción deducida debe ser declarada inadmisible;

VIGESIMOSEXTO. Que en aquellos casos en que el constituyente consideró necesario establecer requisitos específicos para declarar la admisibilidad de un requerimiento lo señaló expresamente, como ocurre respecto de la acción de inaplicabilidad de acuerdo a lo que dispone el artículo 93, inciso decimoprimero, de la Constitución.

Todavía más, en aquellas materias en que le otorgó competencia a estos efectos a la ley orgánica constitucional procedió de la misma forma. Así sucede en relación con la acción antes mencionada, respecto de la cual el propio inciso decimoprimero del artículo 93 de la Carta Fundamental dispone que su admisibilidad se declarará si se cumplen, también, "los demás requisitos que establezca la ley”. Lo mismo ocurre en cuanto a la declaración de inconstitucionalidad de un precepto legal considerado previamente inaplicable, al establecerse en el inciso decimosegundo del artículo 93 de la Ley Suprema que "corresponderá a la ley orgánica constitucional respectiva establecer los requisitos de admisibilidad, en el caso de que se ejerza la acción pública...";

VIGESIMOSÉPTIMO. Que, en este mismo orden de ideas, debe tenerse presente que el restringir el acceso a esta Magistratura estableciendo exigencias no contempladas en el ordenamiento constitucional no se concilia con el espíritu de la Carta Fundamental, que es el permitir que las personas y órganos legitimados

El Tribunal deberá resolver dentro de treinta días, contados desde que quede terminada la tramitación. Podrá prorrogar este plazo hasta por quince días, mediante resolución fundada, si existen motivos graves y calificados.

La sentencia que acoja el requerimiento deberá publicarse en la forma y plazo señalados en el artículo 31 bis. Sin embargo, con el solo mérito de la sentencia que acoja el requerimiento, el decreto quedará sin efecto de pleno derecho."(destacado agregado). 
puedan recurrir en forma expedita ante ella, a fin de que pueda velar por el principio de supremacía constitucional cuya custodia le ha sido encomendada; [...]".

1.2. En cuanto al plazo para promover cuestión de inconstitucionalidad del $\mathrm{N}^{\circ} 7$ del artículo 93 de la Constitución Política de la República; sobre este punto, el Tribunal Constitucional señala, en relación a los artículos 47 O y $47 \mathrm{~S},{ }^{8}$ que el plazo impuesto es inconstitucional por no haber plazo alguno en la Carta para impetrar la acción o declaración:

“SEPTUAGESIMOSEPTIMO. Que, sin embargo, tratándose de la inconstitucionalidad de un precepto legal declarado inaplicable, la Constitución no lo hizo. No consideró conveniente establecer plazo alguno para promover la cuestión, teniendo presente, sin duda, la trascendencia de la atribución entregada a esta Magistratura, que trae como consecuencia, si se resuelve la inconstitucionalidad, que la norma legal, por ser contraria a la Ley Suprema, quede derogada;

SEPTUAGESIMOCTAVO. Que se desprende de lo anterior que, no obstante que en el inciso decimosegundo del artículo 93 de la Constitución se encarga a la ley orgánica constitucional señalar los requisitos de admisibilidad en el caso de ejercerse la acción pública y regular el procedimiento que debe seguirse si se actúa de oficio, no queda comprendido dentro de su competencia establecer un plazo para que la cuestión de inconstitucionalidad sea promovida;

SEPTUAGESIMONOVENO. Que no es posible concluir que haya sido la voluntad del constituyente subordinar el ejercicio de la función de velar por la supremacía constitucional que le ha encomendado a esta Magistratura, en una situación de tanta relevancia que puede determinar que uno o más preceptos legales sean expurgados de nuestro ordenamiento jurídico, a que la cuestión se promueva dentro de un plazo, como lo disponen las normas del proyecto que se analizan; [...]".

8 “Artículo 47 O. En el caso del número $7^{\circ}$ del artículo 93 de la Constitución Política de la República, la cuestión de inconstitucionalidad podrá ser promovida por el Tribunal Constitucional actuando de oficio y por las personas legitimadas a que se refiere el inciso duodécimo del mismo artículo.

La cuestión sólo podrá promoverse dentro de los seis meses siguientes a la fecha de publicación de la sentencia que haya declarado la inaplicabilidad.

Esta cuestión no podrá promoverse respecto de un tratado ni de una o más de sus disposiciones."

"Articulo 47 S. Procederá declarar la inadmisibilidad de la cuestión de inconstitucionalidad promovida mediante acción pública, en los siguientes casos:

$1^{\circ}$ Cuando no exista sentencia previa que haya declarado la inaplicabilidad del precepto legal impugnado; $2^{\circ}$ Cuando la cuestión se funde en un vicio de inconstitucionalidad distinto del que motivó la declaración de inaplicabilidad del precepto impugnado, y

$3^{\circ}$ Cuando se promueva fuera del plazo establecido en el artículo $47 \mathrm{O}$.

Declarada la inadmisibilidad por resolución que deberá ser fundada, se notificará a quien haya recurrido, se comunicará a la Cámara de Diputados, al Senado y al Presidente de la República, y el requerimiento se tendrá por no presentado, para todos los efectos legales.

La resolución que declare la admisibilidad o inadmisibilidad de la cuestión no será susceptible de recurso alguno.".

Cabe señalar que el Tribunal Constitucional, en STC rol 1.288/2008, de 25 de agosto de 2009, declara inconstitucional el inciso segundo del artículo $47 \mathrm{O}$ y el $\mathrm{N}^{\circ} 3$ del inciso primero del artículo $47 \mathrm{~S}$, del proyecto modificatorio de la LOCTC, transcritos anteriormente. 
En nuestro medio, Eduardo Aldunate critica esta declaración de inconstitucionalidad relativa al plazo para promover la cuestión de inconstitucionalidad, ya que, con ello vendría a reforzarse el poder político del Tribunal Constitucional, ilimitando temporalmente el obrar del "legislador negativo".?

1.3. Para concluir, es menester consignar que el Tribunal Constitucional reserva un apartado (o capítulo III) del decisum de la sentencia para la ratio decidendi de la decisión acerca de los "entendidos", es decir, en tal apartado procede a indicar el fundamento del contenido interpretativo de la sentencia (considerandos $90^{\circ}$ a $120^{\circ}$ ) y que es, probablemente, la parte de esta decisión de autocontrol de constitucionalidad que más comprensión generará en el debate académico, ya que, se funda en el principio de competencia tasada y en el principio pro requirente.

Desagregadamente la sentencia del Tribunal Constitucional, por artículos, recoge los siguientes entendidos:

1.3.1. Sobre el artículo $33 \mathrm{~B}$, inciso tercero, relativo al novísimo "abandono del procedimiento", la sentencia señala:

“NONAGESIMOSEPTIMO. Que, atendido el hecho de que el abandono del procedimiento sólo puede hacerse valer respecto de la acción de inaplicabilidad, la referencia que en dicha disposición se hace a una "cuestión de inconstitucionalidad" debe entenderse efectuada a una "cuestión de inaplicabilidad por inconstitucionalidad"; [...]".

1.3.2. Sobre el artículo $47 \mathrm{G}$, inciso primero, $\mathrm{N}^{\circ} 5$, relativo a la relevancia del "precepto legal" en la inaplicabilidad, se indica:

"CENTESIMO. Que, refiriéndose a esta materia, esta Magistratura ha declarado que "tan decisivo en la resolución de un asunto - desde el punto de vista de la preeminencia de los derechos constitucionales- resulta el precepto cuya aplicación puede resolver el fondo del asunto, como el que permite, impide o dificulta ostensiblemente el conocimiento y decisión de la controversia." (Sentencia de 3 de enero de 2008, dictada en los autos Rol $\mathrm{N}^{\circ} 792$, considerando quinto).

Y recientemente ha señalado: "Al actual texto de la Carta Fundamental le basta, para efectos de admitir a tramitación una acción de inaplicabilidad, que el precepto impugnado pueda resultar decisivo en la resolución de un asunto cualquiera, que naturalmente deba resolverse en esa gestión pendiente y que, para efectos del fondo, produzca en esa gestión en que puede aplicarse un resultado contrario a la Constitución." (Sentencia de 2 de abril de 2009, dictada en los autos Rol $\mathrm{N}^{\circ} 1.279$, considerando décimo);

CENTESIMOPRIMERO. Que, de acuerdo con lo que se ha expresado en los considerandos anteriores, la disposición contenida en el $\mathrm{N}^{\circ} 5$ del inciso primero del

9 Aldunate (2009). 
artículo $47 \mathrm{G}$, es constitucional en el entendido que la norma legal objetada a que alude "no ha de tener aplicación" o "no resultará decisiva" en la resolución de "un asunto" y no necesariamente "del asunto" en la gestión pendiente en que incide la acción interpuesta; [...]".

1.3.3. A propósito del artículo $47 \mathrm{G}$, inciso primero, $\mathrm{N}^{\circ} 6$, sobre el comodín procesal de "fundamento plausible" como presupuesto de la inaplicabilidad, el Tribunal Constitucional precisa su encuadramiento:

"CENTESIMOCUARTO. Que el concepto de "fundamento plausible" contenido en la norma en análisis, por su propio significado, se identifica con el de "fundada razonablemente" que, aludiendo a la cuestión planteada, comprende el precepto de la Carta Fundamental;

CENTESIMOQUINTO. Que, por este motivo, este Tribunal considera que la disposición comprendida en el $\mathrm{N}^{\circ} 6^{\circ}$ del inciso primero del artículo $47 \mathrm{G}$, contenido en el artículo único, $\mathrm{N}^{\circ} 57$, del proyecto, es constitucional en el entendido que se refiere a la exigencia contemplada en el artículo 93, inciso decimoprimero, de la Constitución Política, de que la acción sometida a conocimiento de esta Magistratura esté "fundada razonablemente"; [...]".

1.3.4. En relación al artículo $47 \mathrm{~K}$ sobre fundamento de la sentencia de inaplicabilidad, se dispone:

"CENTESIMOSEPTIMO. Que teniendo presente que la norma transcrita alude a la atribución que el artículo 93 , inciso primero, $\mathrm{N}^{\circ} 6^{\circ}$, de la Ley Suprema confiere a este Tribunal, ha de considerarse que es constitucional en el entendido que se refiere a una declaración de "inaplicabilidad por inconstitucionalidad" y no de "inconstitucionalidad" como en ella se indica, de un precepto legal impugnado ante esta Magistratura; [...]".

1.3.5. En lo pertinente al artículo $47 \tilde{\mathrm{N}}$ sobre efecto inter partes y en la gestión judicial de que se trate de la sentencia de inaplicabilidad, se puntualiza que este concierne no al "juicio" sino "gestión", en los términos siguientes:

"CENTESIMONOVENO. Que, como es sabido, en relación con el requerimiento de inaplicabilidad, en la Carta de 1980 se innovó respecto de la Carta de 1925 que permitía su interposición en relación con un "juicio que se siguiere ante otro tribunal".

En la Constitución actual se consideró que debía dársele mayor amplitud al recurso y se reemplazó el término "juicio" por "gestión”, siguiendo asî la línea que jurisprudencialmente había adoptado la Corte Suprema en el mismo sentido; [...]"

“CENTESIMO DECIMOPRIMERO. Que, atendido lo anteriormente expuesto, la disposición en examen es constitucional en el entendido que la alusión al "juicio en que se solicite" la declaración de inaplicabilidad lo es a la "gestión" en que ello ocurra; [...]". 
1.3.6. Sobre los artículos $47 \mathrm{P}, 47 \mathrm{Q}$, inciso primero, y $47 \mathrm{~W}$, concernientes a los antecedentes del requerimiento de la cuestión de inconstitucionalidad, se señala:

“CENTESIMO DECIMOQUINTO. Que dichos preceptos son constitucionales en el entendido que las oraciones "la sentencia de inaplicabilidad que le sirve de sustento", "la sentencia de inaplicabilidad previa en que se sustenta" y "la sentencia previa de inaplicabilidad que le sirve de sustento", contenidas en ellos, aluden a la o a las sentencias de inaplicabilidad en que se base la cuestión promovida o se funde la resolución preliminar o la declaración de inconstitucionalidad a que ellos se refieren, puesto que dichas sentencias pueden ser una o varias en conformidad con lo que dispone el artículo 93 , inciso primero, $\mathrm{N}^{\circ} 7^{\circ}$, de la Constitución; [...]".

1.3.7. Finalmente, del artículo 48 , inciso tercero, sobre antecedentes relativos a "cuestiones sobre la promulgación de una ley", el entendido consigna:

“CENTESIMO DECIMOSEXTO. Que el artículo 48, que el artículo único, $\mathrm{N}^{\circ} 60$, del proyecto introduce al Párrafo $8^{\circ}$ del Título II del Capítulo II de la Ley $\mathrm{N}^{\circ} 17.997$, denominado "Cuestiones sobre la promulgación de una ley", dispone en su inciso tercero, parte primera, lo siguiente:

"Para ser acogido a tramitación el requerimiento deberá cumplir con las exigencias señaladas en el inciso primero del artículo 39 y a él deberá acompañarse copia del oficio de la Cámara de origen que comunica al Presidente de la República el texto aprobado por el Congreso Nacional y, en su caso, copia de la publicación en el Diario Oficial.";

CENTESIMO DECIMOSEPTIMO. Que dicha disposición es constitucional en el entendido que el oficio a que se refiere es aquel que la Cámara de origen envía al Jefe de Estado una vez que el proyecto ha cumplido todos los trámites previstos por la Constitución para la formación de la ley y ha sido definitivamente despachado por el Poder Legislativo, en virtud del cual le comunica el texto del mismo para su promulgación; [...]".

1.3.8. Para concluir, el artículo 50 bis, inciso primero, sobre exigencias del requerimiento impugnatorio de decretales, señala:

"CENTESIMO VIGESIMO. Que, en conformidad con lo dispuesto en el precepto transcrito en el considerando anterior, ha de considerarse que la disposición en examen es constitucional en el entendido que, para ser admitido a tramitación, al requerimiento deberá acompañarse la "publicación o notificación" del decreto objetado; [...]".

2. La STC rol N $1.288 / 2008$, de 25 de agosto de 2009 , recoge una valiosa disidencia de los ministros señores Bertelsen y Vodanovic, acerca de la declaración de constitucionalidad de normas del precepto de ley que modifica la LOCTC del punto resolutivo 17 de la sentencia. Señalan los disidentes acerca de la declaración de constitucionalidad del inciso segundo del artículo 37, artículo 45 bis, $N^{\circ} 2$ del inciso primero del artículo $47 \mathrm{G}$, todos preceptos destinados a cerrar el control de constitucionalidad, cuando mediando 
un control de constitucionalidad ex ante no podrá sucederse en el tiempo un control de constitucionalidad ex post por el mismo vicio que fue objeto de la sentencia:

“2. Que los tres preceptos recién transcritos son inconstitucionales, pues agregan un nuevo requisito de admisibilidad al requerimiento de inaplicabilidad, más allá de lo establecido en el artículo $93, \mathrm{~N}^{\circ} 6$, e inciso decimoprimero de la Constitución, debiendo tenerse presente que el inciso decimoprimero referido, al hablar de "los demás requisitos que establezca la ley", se refiere a requisitos generales de admisibilidad de la acción y no a nuevos requisitos que, yendo más allá del texto de la Constitución, hagan más gravoso el ejercicio del requerimiento de inaplicabilidad, desnaturalizándolo, restando atribuciones al Tribunal Constitucional y poniendo en riesgo la supremacía constitucional.

Que los preceptos en comento, además, desconocen las importantes diferencias entre la actual acción de inaplicabilidad y la que era de competencia de la Corte Suprema con anterioridad a la reforma constitucional del año 2005. En efecto, en virtud de esta reforma se sustituyó el antiguo artículo 83 de la Constitución por el actual artículo 93, eliminando el inciso final de aquél, que disponía que la Corte no podía declarar inaplicable un precepto legal por el mismo vicio, si el Tribunal Constitucional lo había declarado previamente constitucional. Esta eliminación no es sino una consecuencia de los cambios que se efectuaron a la acción de inaplicabilidad, manifestados en el actual artículo 93 de la Constitución, que hoy contempla una clara diferencia entre el control abstracto de constitucionalidad (números $1^{\circ} \mathrm{y}$ $3^{\circ}$ del artículo 93 de la Constitución) y el control concreto que tiene lugar en sede de inaplicabilidad (número $6^{\circ}$ del artículo 93 de la Constitución);

3. Que, como este Tribunal ha dicho en reiteradas sentencias (vid. roles $\mathrm{N}^{\text {os }} 478$, $546,473,517,535,588,589,106,608$ y 623 , entre otros), reflexionando sobre la naturaleza de la actual acción de inaplicabilidad y sus diferencias con la similar prevista en la Carta Fundamental con anterioridad a la reforma del año 2005, destaca especialmente "la constatación de que de la simple comparación del texto de la norma actual con el antiguo artículo 80 de la Carta Fundamental, que entregaba esta facultad a la Corte Suprema, se desprende que mientras antes se trataba de una confrontación directa entre la norma legal y la disposición constitucional, ahora se está en presencia de una situación diferente, por cuanto lo que podrá ser declarado inconstitucional, por motivos de forma o de fondo, es la aplicación del precepto legal impugnado a un caso concreto, lo que relativiza el examen abstracto de constitucionalidad, marcando así una clara diferencia con la regulación prevista por el texto constitucional anterior". Además, "lo dicho deja de manifiesto que las características y circunstancias del caso concreto de que se trate, han adquirido en la actualidad una relevancia mayor de la que debía atribuírseles antes de 2005 pues, ahora, la decisión jurisdiccional de esta Magistratura ha de recaer en la conformidad o contrariedad con la Constitución que la aplicación del precepto impugnado pueda tener en cada caso concreto, lo que no implica, necesariamente, una contradicción abstracta y universal con la preceptiva constitucional" ( Rol N$^{\circ} 608$, considerando decimoprimero);

4. Que, por tanto y conforme a la naturaleza de la actual acción de inaplicabilidad, puede perfectamente ocurrir que una norma en abstracto sea constitucional, pero 
en concreto -en su aplicación a una gestión pendiente que se siga ante un tribunal- sea inconstitucional, y esta Magistratura debe hacerse cargo de ello; [...]".

\section{CONCLUSIONES}

Puesto ante la necesidad de concluir este trabajo una afirmación ritual, pero indispensable, es postular la necesidad de conciliar el principio pro requirente, la actitud institucional de la Judicatura pro admitiere y su imbricación con el activismo judicial, con las exigencias impuestas por la autolimitación (self restraint) del Tribunal Constitucional, órgano jurisdiccional de tutela judicial de la Constitución o Derecho de la Constitución, que ante el control de constitucionalidad de actos estatales y en especial de la ley, a partir del principio de separación de poderes y del principio democrático, requiere de admitir una presunción de constitucionalidad que sólo cede cuando "[...] la oposición del acto sospechoso y la Carta Fundamental fuera concluyente" y también exige de un mínimo de deferencia hacia los poderes públicos para que el "orden institucional funcione de manera armónica y eficiente". ${ }^{10}$

La sentencia comentada viene a reponer una actitud pro admitiere del Tribunal Constitucional y recepciona un principio pro requirente, como ejes de argumentación o ratio decidendi acerca de las decisiones de inconstitucionalidad y "entendidos", con una adecuada excusa, la defensa de su competencia tasada, pero que permite abrir la tutela judicial del Derecho de la Constitución a los legitimados activamente, sin sacrificar la activación de la Judicatura a excesos formalistas.

Por otra parte, el principio pro requirente expresa en la sentencia comentada, una decisión político-institucional del Tribunal Constitucional de impedir la desconstitucionalización de su competencia y vaciamiento legislativo, a través de una legislación orgánico constitucional relativa a procedimientos, que condensan las reglas del proceso constitucional. Ciertamente, esta decisión político-institucional utiliza como excusa la desconstitucionalización y vaciamiento en que el legislador orgánico constitucional de la Constitución puede incurrir, y para ello el principio pro requirente también es un comodín justificatorio de declaraciones de inconstitucionalidad y "entendidos" del Tribunal Constitucional, que vienen a poner en tela de juicio la aptitud o idoneidad y profundidad normativas del legislador y de la ley orgánica constitucional en este caso para el desarrollo de la Constitución.

En otro orden de materias, llama poderosamente la atención que la sentencia se haga cargo de una regla de cierre o complitud del control de constitucionalidad, que busca impedir que al control de constitucionalidad ex ante se suceda y superponga el control de constitucionalidad ex post, cuando se trate del mismo vicio de inconstitu-

10 En nuestra doctrina son trabajos valiosos de SiLVA BASCuñán (2003), pp. 71-82; Zapata LaRraín (2008), pp. 243 y 227; y BRUNet Bruce (2006). 
cionalidad, regla contenida en el inciso final del artículo 83 de la Constitución antes de la reforma constitucional de 2005, regla que demostró su perfecta inutilidad e inconveniencia, limitando severamente el campo del control de constitucionalidad, momento del control (preventivo y represivo) y naturaleza de este (abstracto y concreto), haciendo tabula rasa nuevamente en materia de "vicios de inconstitucionalidad", cuando se producen estos en base al conflicto constitucional que esta Judicatura debe heterocomponer.

En este sentido, la citada fragmentariamente disidencia de los ministros señores Bertelsen y Vodanovic me parece bien encaminada al desnudar los problemas que plantea la reposición de esta regla en los artículos 37 (inciso segundo nuevo), 45 bis y $47 \mathrm{~F} \mathrm{~N}^{\circ} 2$ (antiguo $47 \mathrm{G}$ ) todos de la Ley $\mathrm{N}^{\circ} 20.381$.

En suma sólo resta agregar una suerte de ambivalencia teórico-práctica en nuestras conclusiones: por una parte el principio pro requirente muestra el lado más amable o positivo en la sentencia de autocontrol de constitucionalidad que comentamos al dejar abierta, dentro de una competencia tasada, la justiciabilidad de la Constitución; y por otra parte es obligado advertir que, bajo este principio y la actitud pro admitiere, el Tribunal desplegó en el pasado una funcionalidad autoritaria y contramayoritaria; y en el presente por venir late el peligro de un acusado y disfrazado activismo judicial, grave patología que afecta a la jurisdicción constitucional en su práctica efectiva.

\section{BIBLIOGRAFÍA CITADA}

AldunAte L., Eduardo (2009): “La ingenuidad de un poder”, en Blog Columna Constitucional, [fecha de consulta: $1^{\circ}$ de octubre de 2009]. Disponible en: http:// columnaconstitucional.blogspot.com/2009/10/la-ingenuidad-de-un-poder.html.

Brunet Bruce, Marcelo (2006): "Admisibilidad en materias constitucionales: Principio in dubio pro admitiere”, en XXXVI Jornadas Chilenas de Derecho Público (Santiago, Facultad de Derecho, Universidad de Chile).

Carmona S., Carlos (2001): "El principio pro requirente en la jurisprudencia del Tribunal Constitucional”, en Revista de Derecho Público (Nº3), pp. 564-600.

Couture, Eduardo J. (1958): Fundamentos de Derecho Procesal Civil (Buenos Aires, Ediciones Depalma).

Fix ZAmudio, Héctor (1985): "Ejercicio de las garantías constitucionales sobre la eficacia del proceso", en IX Jornadas Iberoamericanas de Derecho Procesal” (Madrid).

GarCía de ENTERRía, Eduardo (1985): La Constitución como norma y el Tribunal Constitucional. $3^{\text {a }}$ Edición. (Madrid, Civitas).

Kelsen, Hans (2001): La Garantía Jurisdiccional de la Constitución (La Justicia Constitucional) (Traducc. Rolando Tamayo Salmorán, México, Universidad Nacional Autónoma de México).

Silva Bascuñán, Alejandro (2003): Tratado de Derecho Constitucional. $2^{\text {a }}$ Edición (Santiago, Editorial Jurídica de Chile), Tomo IX. 
Zapata Larraín, P. (2008): Justicia Constitucional. Teoría y práctica en el Derecho Chileno y Comparado (Santiago, Editorial Jurídica de Chile).

ZúÑIGA UrBina, Francisco (2002): Elementos de Jurisdicción Constitucional. 2 Vol. (Santiago, Universidad Central de Chile, Facultad de Ciencias Jurídicas y Sociales), $1^{\circ}$ vol., 225 pp., $2^{\circ}$ vol., 279 pp.

ZúNIIGA URBINA, Francisco (2006): "Refundación del Tribunal Constitucional chileno", en Revista Peruana de Derecho Público (Año 7, № 12), Sección Estudios, pp. 151-165. 